\title{
Reaction Characteristics of Hydrogen-Rich Syngas Production by Sludge/Coal Cogasification Based on the Iron-Based Oxygen Carriers
}

\author{
Qingjiao Zhu, Xintong Guo, Yanan Guo, Jingjing Ma, Qingjie Guo* \\ State Key Laboratory of High-efficiency Utilization of Coal and Green Chemical Engineering, Ningxia University, Yinchuan, \\ 750021, China \\ E-mail: qingjjie_guo@163.com
}

Received: 7 September 2021; Revised: 27 December 2021; Accepted: 31 December 2021

\begin{abstract}
With the acceleration of industrialization and urbanization in China, wastewater treatment is increasing yearly. As a by-product of wastewater treatment, the gasification of sludge with coal in chemical looping process is a clean and efficient conversion technology. To explore the reaction behavior of cogasification of sludge and coal with iron-based oxygen carriers (OCs) for producing hydrogen-rich syngas, the experiment of cogasification using $\mathrm{Fe}_{2} \mathrm{O}_{3} /$ $\mathrm{Al}_{2} \mathrm{O}_{3}$ as $\mathrm{OC}$ in a fluidized bed reactor was conducted. The result showed that the volume percentage of hydrogen $\left(\mathrm{H}_{2}\right)$ and syngas yield is proportional to the amount of sludge added. The optimal operation conditions were: temperature at $900{ }^{\circ} \mathrm{C}$, the mass ratio of $\mathrm{OC}$ to coal at 5.80 and mass ratio of sludge to coal at 0.2 . Under this operating condition, the volume percentage of $\mathrm{H}_{2}$ and syngas yield in the flue gas was $75.6 \mathrm{vol} \%$ and $97.5 \mathrm{~L} \cdot \mathrm{min}^{-1} \cdot \mathrm{kg}^{-1}$, respectively. Besides, the OC showed a stable reactivity in the sixth redox cycle with added sludge. However, the reactivity of OC significantly declined in the seventh and eighth redox cycles. It was recovered when the ash was separated. The decrease in the specific surface area of the OC caused by ash deposition is the main reason for the decline in its reactivity. The kinetic analysis showed that the random pore model describes the reaction mechanism of sludge/coal chemical looping gasification (CLG). The addition of sludge can reduce the activation energy of coal CLG reaction, accelerate the gasification reaction rate and increase the carbon conversion.
\end{abstract}

Keywords: sludge, CLG, oxygen carriers, hydrogen-rich syngas

\section{Introduction}

Sludge is terminal product of wastewater treatment, with complex compositions, including pollutants, various prokaryotic microorganisms, heavy metals, radioactive elements, and other refractory substances in sewage. ${ }^{1}$ If not treated effectively and reasonably, it will have a substantially adverse impact on the environment, thereby endangering people's health. In addition, the sludge contains rich nitrogen, phosphorus, and other elements, which is economically beneficial if utilized reasonably. Currently, the domestic sludge treatment process is only a simple modulationdewatering-filling system, ${ }^{2}$ resulting in the phenomenon of "sludge siege" in many cities with low sludge treatment levels, significantly polluting the air, soil, and groundwater. The water content in general sludge is as high as $98 \%$. The sludge can be cogasified with other substances (traditional Chinese medicine slag, straw, garbage, anthracite) ${ }^{3-7}$ to effectively reduce sludge volume, removing the heavy metals along with the ash. ${ }^{8,9}$

Copyright (C2022 Qingjie Guo, et al.

DOI: https://doi.org/10.37256/fce.3120221138

This is an open-access article distributed under a CC BY license

(Creative Commons Attribution 4.0 International License)

https://creativecommons.org/licenses/by/4.0/ 
Coal is a primary fuel, and previous studies on cogasification of coal and sludge have been conducted. García et al. ${ }^{10}$ studied the cogasification characteristics of sludge and coal in a laboratory-scale fluidized bed reactor. The results showed that the ratio of $\mathrm{H}_{2}$ to $\mathrm{CO}$ in syngas significantly increased after adding the sludge. Jeong et al. ${ }^{11}$ used a twostage gasifier composed of a fluidized bed gasifier and tar cracking reactor to cogasify coal and dry sludge, and obtained $27.7 \mathrm{vol} \% \mathrm{H}_{2}$ syngas at the reactor outlet.

At present, the conventional gasification method has a higher cost and significant $\mathrm{CO}_{2}$ emissions. Chemical looping gasification (CLG) is a new technology ${ }^{12}$ (Figure 1) based on chemical looping combustion. Compared with conventional coal gasification, CLG eliminates the air separation and oxygen generator, thus reducing the power consumption of oxygen generation. In addition, the acid gas removal device is simplified by controlling NOx formation. At the same time, by adjusting the amount of gasification agent to be added and the circulation rate of oxygen carriers (OCs), the composition of syngas and the hydrogen-carbon ratio can be adjusted flexibly to obtain syngas with $\mathrm{H}_{2}$ and $\mathrm{CO}$ as the main components. ${ }^{13-16}$ As an indispensable key material in the CLG technology, the iron-, nickel-, copper-, or manganese-based metal oxide are usually used as OC. Iron-based OC has been widely studied and applied in chemical looping technology due to its low cost and environmental friendliness. ${ }^{17-20}$

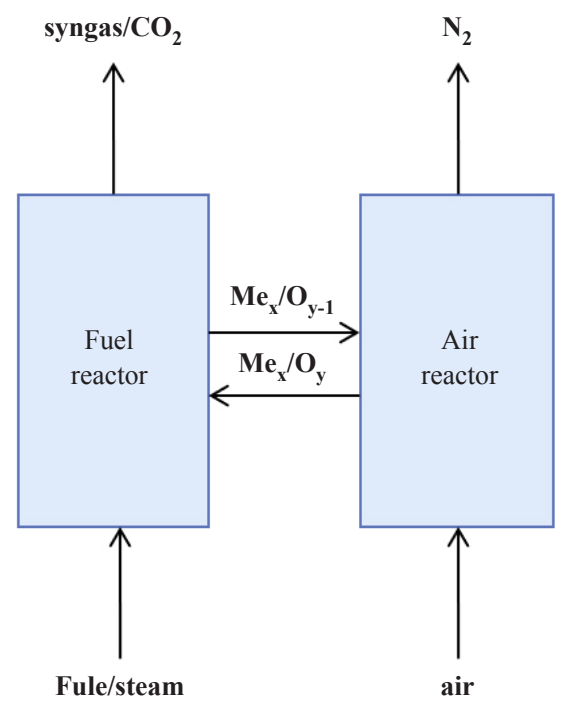

Figure 1. Schematic diagram of CLG

The kinetic expressions describing CLG are usually based on gas-solid reactions, so the following three models are commonly used to describe their reaction processes: volume reaction model (VRM), shrinking core model (SCM), and random pore model (RPM), as shown in Table 1..$^{21,22}$ The VRM assumes that the reaction occurs uniformly in the solid particles (OCs), such that there is no film diffusion resistance. During the reaction process, the particle volume is constant but with variable density. The SCM assumes that the reaction occurs on the surface of the solid particles and gradually moves from the surface to the interior. The effects of gas film and ash layer diffusion are not considered in the reaction. The RPM assumes that the pores inside the particles are the randomly distributed cylindrical pores with different sizes and directions, overlapping each other and the reaction occurs on the pore wall. The influence of the change in the pore structure of solid particles on the gasification reaction rate was described, which was suitable for the case reaction rate. Regardless of the influence of diffusion resistance, it is assumed that the product structure does not affect the reaction process. 
Table 1. Three typical gas-solid reaction kinetics models ${ }^{21,22}$

\begin{tabular}{cc}
\hline Model & Expression \\
\hline Volume reaction model & $\frac{\mathrm{d} x}{\mathrm{dt}}=\mathrm{k}(1-x)$ or $-\ln (1-x)=\mathrm{kt}$ \\
Shrinking core model & $\frac{\mathrm{d} x}{\mathrm{dt}}=\mathrm{k}(1-x)^{2 / 3}$ or $3\left(1-(1-x)^{1 / 3}\right)=\mathrm{kt}$ \\
Random pore model & $\frac{\mathrm{d} x}{\mathrm{dt}}=\mathrm{k}(1-x) \sqrt{1-\varphi \ln (1-x)}, \varphi=\frac{2}{2 \ln \left(1-x_{\max }\right)}$ or $\frac{2}{\varphi}(\sqrt{1-\varphi \ln (1-x)}-1)=\mathrm{kt}$ \\
\hline
\end{tabular}

This research studied the reaction characteristics and kinetics of S/C CLG with iron-based OC in a fluidized bed reactor. As a result, the optimal conditions and circulating reaction characteristics were obtained.

\section{Materials and methods}

\subsection{Material preparation}

Sludge (taken from the third sewage treatment plant in the Xixia district of Yinchuan city) and Xinjiang bituminous coal were used as the experimental fuels. The coal and sludge were respectively dried in air at room temperature and pressure, then placed in a drying oven at $100{ }^{\circ} \mathrm{C}$ to a constant weight for analysis and characterization. The industrial analysis and elemental analysis of the air-dry basis are shown in Table 2. The particle size of bituminous coal was $0.15-0.27 \mathrm{~mm}$. The dry sludge samples with a particle size of $0.27-0.55 \mathrm{~mm}$ were selected for the experiment. The composition is shown in Table 3.

Table 2. Proximate and ultimate analysis of dry sludge and Xinjiang bituminous coal

\begin{tabular}{ccccccccccc}
\hline & \multicolumn{3}{c}{ Proximate analysis, adb, wt $\%$} & \multicolumn{5}{c}{ Ultimate analysis, adb, wt $\%$} \\
\cline { 2 - 10 } Sample & M & A & V & FC & C & H & N & S & O \\
\hline DS & 7.00 & 52.32 & 33.91 & 6.77 & 15.89 & 2.69 & 2.13 & 0.50 & 19.47 \\
XJ & 9.06 & 3.55 & 28.07 & 59.32 & 76.06 & 3.5 & 0.29 & 0.44 & 15.83 \\
\hline
\end{tabular}

adb: air-dry based

M: moisture

A: ash

$\mathrm{V}$ : volatile matter

FC: fixed carbon

XJ: Xinjiang bituminous coal

DS: dry sludge

$\mathrm{Wt} \%$ of $\mathrm{O}$ element was calculated by difference

Table 3. Ash composition of the dry sludge

\begin{tabular}{ccccccccc}
\hline Oxide & $\mathrm{SiO}_{2}$ & $\mathrm{Fe}_{2} \mathrm{O}_{3}$ & $\mathrm{CaO}$ & $\mathrm{Al}_{2} \mathrm{O}_{3}$ & $\mathrm{SO}_{3}$ & $\mathrm{MgO}$ & $\mathrm{K}_{2} \mathrm{O}$ & $\mathrm{Na}_{2} \mathrm{O}$ \\
\hline Content $(\mathrm{wt} \%)$ & 30.36 & 29.31 & 15.03 & 11.00 & 2.28 & 1.59 & 0.88 & 0.85 \\
\hline
\end{tabular}




\subsection{Preparation and characterization of oxygen carrier}

The $\mathrm{Fe}_{2} \mathrm{O}_{3} / \mathrm{Al}_{2} \mathrm{O}_{3}$ OC was prepared by mechanical mixing with $\mathrm{Fe}_{2} \mathrm{O}_{3}$ as an active component and $\mathrm{Al}_{2} \mathrm{O}_{3}$ as the inert carrier. The specific methods are: $\mathrm{Fe}_{2} \mathrm{O}_{3}$ and $\mathrm{Al}_{2} \mathrm{O}_{3}$ (AR, Sinopharm Chemical reagent Co., Ltd.) are put into the colloid-grinder according to the mass ratio of 7:3 with mechanical stirring for 15-20 min. After filtering, the filter cake is dried in an oven at $110^{\circ} \mathrm{C}$ for $24 \mathrm{~h}$, and the dried filter cake is calcined in a muffle furnace at $1100{ }^{\circ} \mathrm{C}$ for $3 \mathrm{~h}$. Finally, the calcined OCs are crushed and sieved to the particle size of $0.15-0.27 \mathrm{~mm}$, and this $\mathrm{OC}$ is briefly denoted as $\mathrm{Fe}_{7} \mathrm{Al}_{3}$, expressed as OC.

The microstructure of OCs was determined by scanning electron microscope (SEM) of Regulus 8100 in Japan. In addition, the phase composition and crystal structure of OCs were analyzed by D8 ADVANCE A25 X-ray diffractometer (XRD).

\subsection{Experimental setup and procedure}

The S/C CLG device is shown in Figure 2. The experimental device consists of a gas distribution system (argon, air, and water steam), temperature control system, fluidized bed reactor, circulating condensation system, gas collection, and detection system. The inner diameter of the fluidized bed reactor is $30 \mathrm{~mm}$ and the length is $900 \mathrm{~mm}$. The gas produced during the reaction was condensed, dried, and then entered in gas chromatography for gas content and composition analysis.

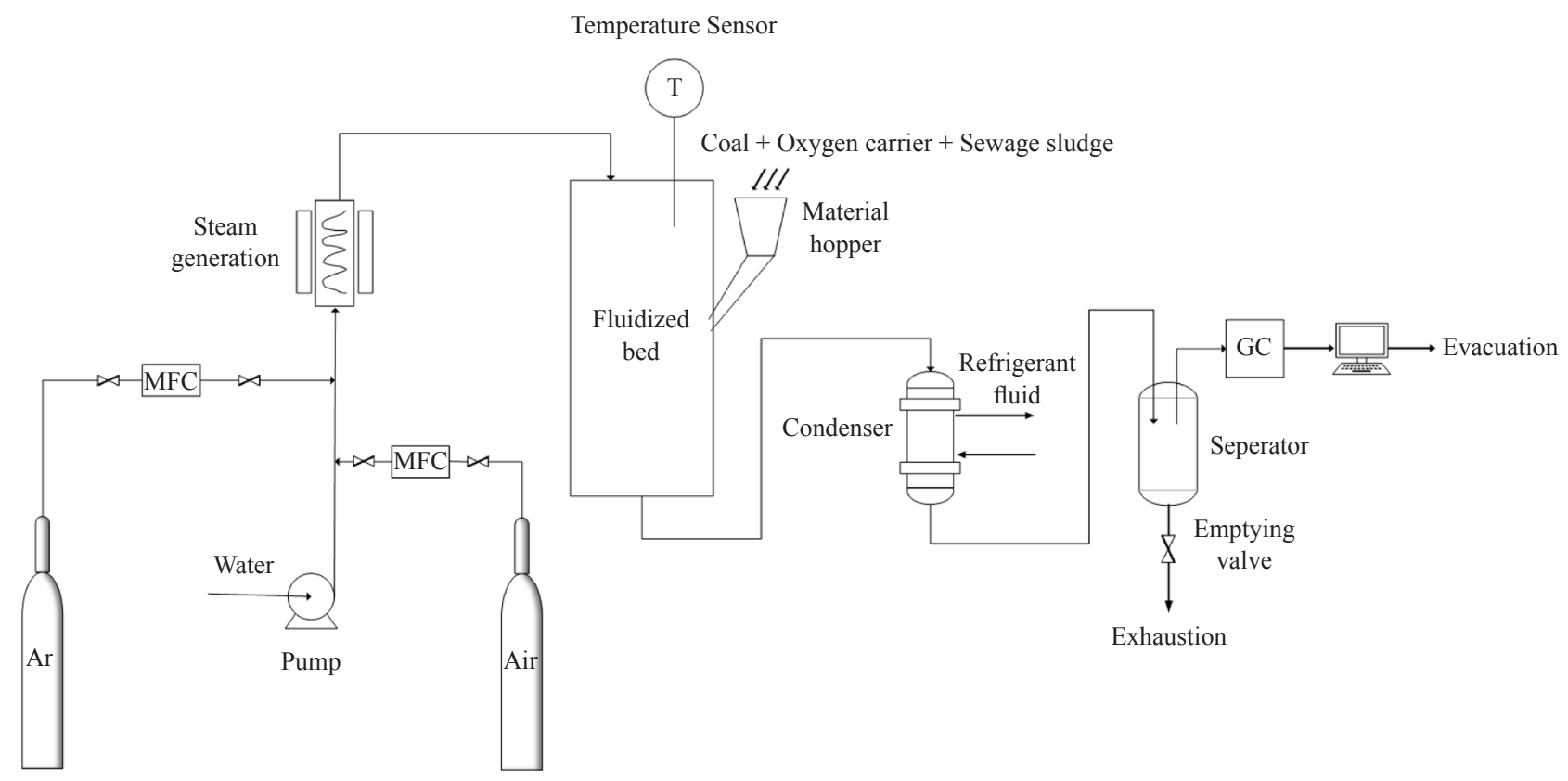

Figure 2. Schematic diagram of the experimental device

The equipment was checked to be airtight before the experiment, and the specific operating conditions are shown in Table 4. The reduction temperature set in the reactor is used to calculate the water steam volume. After the bed temperature reached the preset reaction temperature, the carrier gas and steam generator were opened to replace the gas (air) in the bed. After $3 \mathrm{~min}$, the coal, OCs, and sludge mixture were blown into the bed through the feeder. In order to prevent the carrier gas from being blown into the reactor from having a significant impact on the gas phase concentration in the reactor, a small sealed feed hopper is adopted to apply pressure higher than 2 bar of the reactor, and only trace airflow is used to blow particles into the reactor. At the moment of feeding, the temperature fluctuations 
in the reactor is less than $5{ }^{\circ} \mathrm{C}$ (for $900{ }^{\circ} \mathrm{C}$, the influence of $5{ }^{\circ} \mathrm{C}$ fluctuations on temperature is less than $1 \%$ ), and the operating temperature will be quickly restored in $2 \mathrm{~min}$. The carrier gas flow should be reduced or closed during the feeding to avoid the material being blown out reversely by excessive airflow in the bed. After the feeding, the argon gas should be adjusted to the proper flow for gasification reaction. After the reaction, the steam generator was shut down, and the reaction gas was switched to air for OCs' oxidation. It should be noted that in the cycling experiment, after the reduction experiment, nitrogen purge is needed to replace the reducing atmosphere and water steam, and then switch to air for oxidation.

Table 4. Experimental operating conditions

\begin{tabular}{ccc}
\hline Item & Parameter & Value \\
\hline $\mathrm{Fe}_{7} \mathrm{Al}_{3}$ & Mass $/ \mathrm{g}$ & $8.70-14.48$ \\
Coal & Mass $/ \mathrm{g}$ & 2 \\
Sewage sludge & Mass $/ \mathrm{g}$ & $0-1.0$ \\
Purge gas (Ar) & Volume flow rate of $\mathrm{Ar} / \mathrm{L} \cdot \mathrm{min}^{-1}$ & 0.6 \\
Reduction test & Volume fraction rate of $\mathrm{H}_{2} \mathrm{O} / \mathrm{vol} \%$ & 75 \\
& Temperature $/{ }^{\circ} \mathrm{C}$ & $800-950$ \\
& Time $/ \mathrm{min}$ & 60 \\
& Volume flow rate of air $/ \mathrm{L} \cdot \mathrm{min}^{-1}$ & 0.6 \\
Oxidation test & Temperature $/{ }^{\circ} \mathrm{C}$ & 900 \\
& Time $/ \mathrm{min}$ & 30
\end{tabular}

\subsection{Data evaluation}

\subsubsection{Water steam volume fraction}

Define water steam volume fraction as the ratio of water steam volume flow to total volume flow, vol\%.

$$
\varphi_{\mathrm{H}_{2} \mathrm{O}(\mathrm{g})}=\frac{L_{\mathrm{H}_{2} \mathrm{O}(\mathrm{g})}}{L_{\mathrm{H}_{2} \mathrm{O}(\mathrm{g})}+L_{\mathrm{Ar}}} \times 100 \%
$$

$L_{\mathrm{H}_{2} \mathrm{O}(\mathrm{g})}+L_{\mathrm{Ar}}$ represents the volume flow of water steam and $\mathrm{Ar}, \mathrm{L} \cdot \mathrm{min}^{-1}$.

\subsubsection{Gas production}

The gas production $\mathrm{V}_{\text {total }}$ is defined as the gas volume produced during the gasification experiment, $\mathrm{L}$.

$$
\mathrm{V}_{\text {total }}=\int_{0}^{t} \frac{\mathrm{V}_{\mathrm{Ar}}\left(\xi_{\mathrm{CO}}+\xi_{\mathrm{CO}_{2}}+\xi_{\mathrm{CH}_{4}}+\xi_{\mathrm{H}_{2}}\right)}{1-\left(\xi_{\mathrm{CO}}+\xi_{\mathrm{CO}_{2}}+\xi_{\mathrm{CH}_{4}}+\xi_{\mathrm{H}_{2}}\right)} \mathrm{d} t
$$

In the formula, $\mathrm{V}_{\mathrm{Ar}}$ is the volume of inert gas Ar into the gasification reaction within $60 \mathrm{~min}, \mathrm{~L} ; \xi_{\mathrm{CO}}, \xi_{\mathrm{CO}_{2}}, \xi_{\mathrm{CH}_{4}}, \xi_{\mathrm{H}_{2}}$ are the volume fractions of $\mathrm{CO}, \mathrm{CO}_{2}, \mathrm{CH}_{4}$, and $\mathrm{H}_{2}$ in the outlet gas during the gasification experiment, respectively. 


\subsubsection{Synthesis gas production}

Syn is defined as the volume sum of $\mathrm{H}_{2}, \mathrm{CH}_{4}$, and $\mathrm{CO}$ produced per $\mathrm{kg}$ coal feed per minute, $\mathrm{L} \cdot \mathrm{min}^{-1} \mathrm{~kg}^{-1}$.

$$
\mathrm{Syn}=\frac{\mathrm{V}_{\text {total }}\left(\xi_{\mathrm{H}_{2}}+\xi_{\mathrm{CH}_{4}}+\xi_{\mathrm{CO}}\right)}{t \times m_{\mathrm{coal}}} \times 1000
$$

In the formula, $m_{\text {coal }}$ is the coal mass added to the reactor, $\mathrm{g}$.

\subsubsection{Carbon conversion}

Carbon conversion in coal gasification includes pyrolysis and gasification of fixed carbon. The carbon conversion is defined as the ratio of the converted carbon in time $t$ to the carbon content in the initial coal, \%. Gasification rate refers to the conversion rate of carbon during coal gasification. The slope of carbon conversion is the gasification rate, $\%$.

$$
\mathrm{X}_{\mathrm{C}}=\frac{12 \times \int_{0}^{t} \mathrm{~V}_{\text {total }}\left(\xi_{\mathrm{CO}}+\xi_{\mathrm{CO}_{2}}+\xi_{\mathrm{CH}_{4}}\right) \mathrm{d} t}{m_{\text {coal }} x_{\text {coal }} \mathrm{V}_{\mathrm{m}}^{\prime}}
$$

In the formula, $m_{\text {coal }}(\mathrm{g})$ is the coal mass added to the reactor, $x_{\text {coal }}(\mathrm{wt} \%)$ is the carbon content in Xinjiang coal element analysis, and $\mathrm{V}_{\mathrm{m}}^{\prime}\left(\mathrm{L} \cdot \mathrm{mol}^{-1}\right)$ is the gas molar volume at room temperature, where $\mathrm{V}_{\mathrm{m}}^{\prime}=\frac{22.4 \times(273+T)}{273} ; T\left({ }^{\circ} \mathrm{C}\right)$ is room temperature.

\section{Results and discussion}

\subsection{Effect of reaction conditions on reaction characteristics of CLG}

\subsubsection{Reaction temperature}

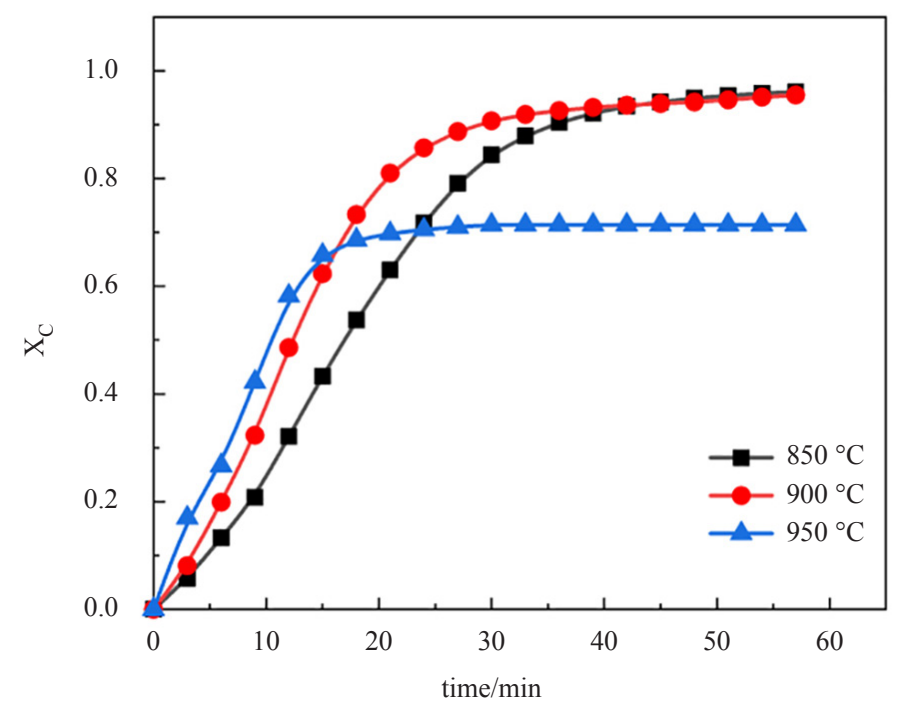

Figure 3. Carbon conversion at different temperatures 
The temperature has an important influence on the CLG process. Therefore, the characteristics of S/C CLG at different reaction temperatures were investigated. Figure 3 shows the dynamic variation of outlet $\mathrm{CO}$ concentration at different reaction temperatures. From the figure, the reaction time at $850{ }^{\circ} \mathrm{C}, 900{ }^{\circ} \mathrm{C}$, and $950{ }^{\circ} \mathrm{C}$ is 30,27 , and 21 min, respectively, and the slope of carbon conversion indicates that the gasification reaction rate increases with the temperature and the reaction time is shortened. The main reason is that the gasification reaction of coke is endothermic, and the increase at the reaction temperature is thermodynamically and kinetically beneficial to the reaction (Figure 4). Figure 4 shows the Gibbs free energy and equilibrium constant calculated based on the stoichiometry in the reaction equation.

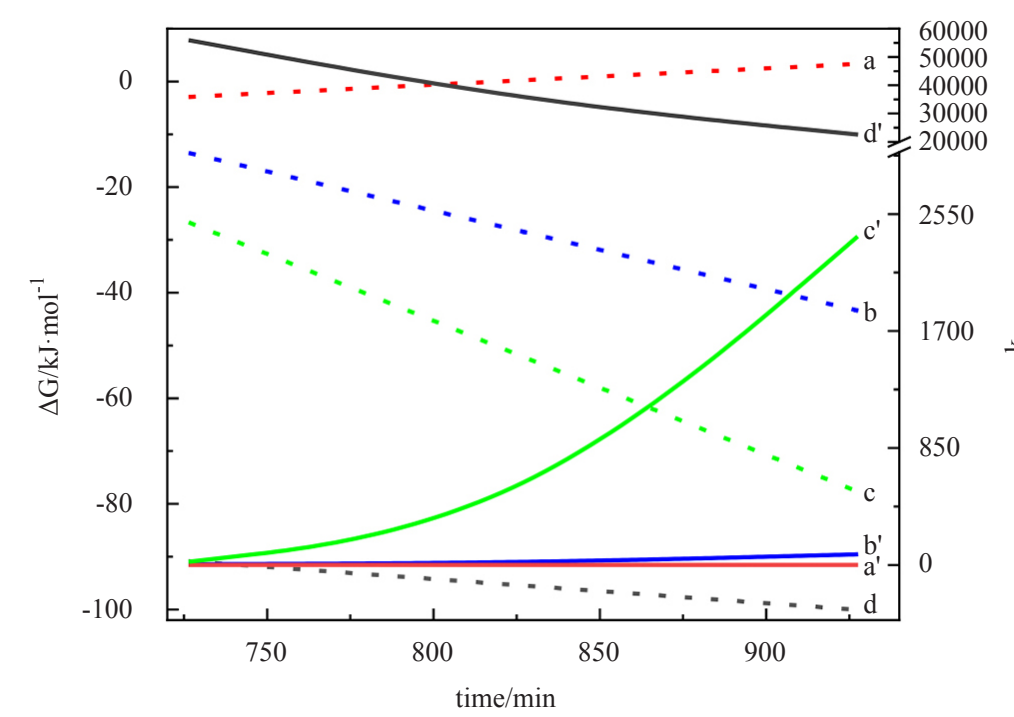

Figure 4. Change in Gibbs free energy (scattered point) and equilibrium constant (solid line) with temperature a, $\mathrm{a}^{\prime}$ : Water-gas shift reaction $\left(\mathrm{H}_{2} \mathrm{O}+\mathrm{CO} \rightarrow \mathrm{CO}_{2}+\mathrm{H}_{2}\right)$

b, $\mathrm{b}^{\prime}$ : Gasification reaction of carbon $\left(\mathrm{C}+\mathrm{H}_{2} \mathrm{O} \rightarrow \mathrm{H}_{2}+\mathrm{CO}\right)$

c, $\mathrm{c}^{\prime}$ : Methane reforming reaction $\left(\mathrm{CH}_{4}+\mathrm{H}_{2} \mathrm{O} \rightarrow \mathrm{CO}+3 \mathrm{H}_{2}\right)$

$\mathrm{d}, \mathrm{d}^{\prime}$ : Oxygen carrier reduction reaction

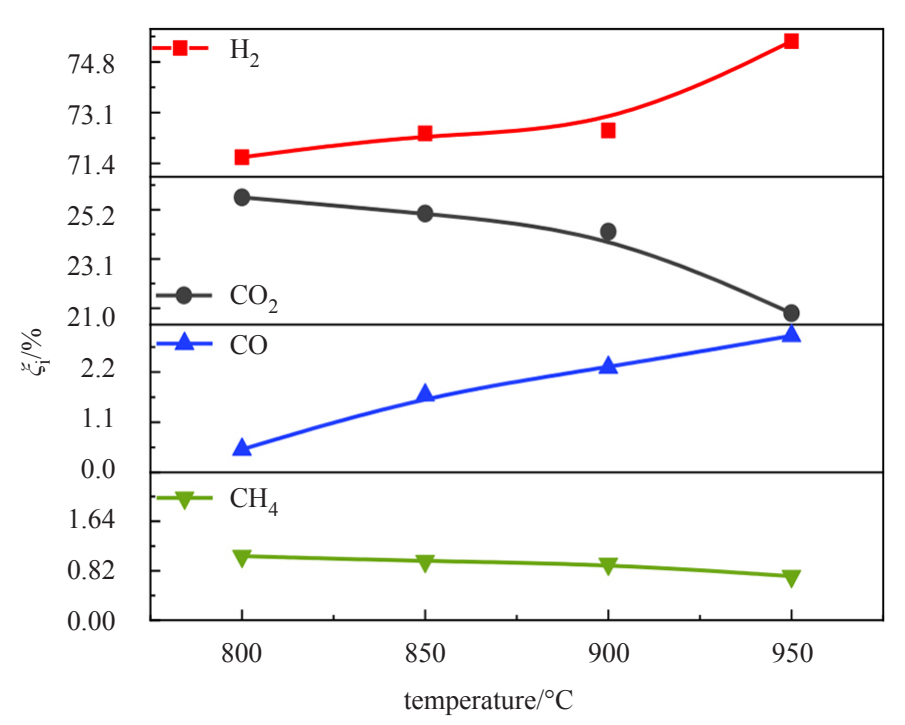

Figure 5. Effect of reaction temperature on the concentration of each component 
Figure 5 shows the effects of different reaction temperatures on the concentration of each gas component, while $\xi_{\mathrm{H}_{2} \mathrm{O}}=72 \%, \mathrm{O} / \mathrm{C}=0.8, \mathrm{~S} / \mathrm{C}=0.2$. With the increase in reaction temperatures, the concentrations of $\mathrm{H}_{2}$ and $\mathrm{CO}$ gradually increased, while the concentration of $\mathrm{CO}_{2}$ gradually decreased. Figure 3 shows that when the reaction temperature is lower than $850{ }^{\circ} \mathrm{C}$, thermodynamically low temperature is beneficial to the forward reaction of water-gas conversion, resulting in a high $\mathrm{CO}_{2}$ concentration in tail gas and a low $\mathrm{CO}$ concentration. At $850-900{ }^{\circ} \mathrm{C}$, a thermodynamically high temperature is not conducive to $\mathrm{CO}$ oxidation reaction, and the formation of $\mathrm{CO}_{2}$ is reduced. With the increase in reaction temperature, the gasification reaction rate of carbon accelerated, which is useful for the positive reaction and generation of $\mathrm{CO}$ and $\mathrm{H}_{2}$. At the same time, the increase in temperature accelerates the methane reforming reaction rate, further promotes the formation of $\mathrm{CO}$ and $\mathrm{H}_{2}$, increases the concentrations of $\mathrm{CO}$ and $\mathrm{H}_{2}$, and decreases the concentration of $\mathrm{CH}_{4}$.

Kinetically, the higher the reaction temperature, the faster the gasification reaction rate, and the shorter the reaction time. But extremely high reaction temperatures will result in the sintering of OCs. ${ }^{23}$ However, the alkali metals in the sludge also play a particular role in promoting the sintering of OCs due to their low melting temperature. Figure 6 compares the morphology changes before and after the reduction of oxygen at different temperatures. When the reaction temperature was $900{ }^{\circ} \mathrm{C}$, the water steam conversion reactione reduced OC after the reaction was still in the form of small particles, and the pore size changed slightly compared with that before the reaction. However, when the reaction temperature is $950{ }^{\circ} \mathrm{C}$, the particle size of the OCs significantly increases, surface structure tends to be smooth, pore size decreases, and the sintering phenomenon occurs. Therefore, $900{ }^{\circ} \mathrm{C}$ was selected as the reaction temperature in the subsequent experiments.
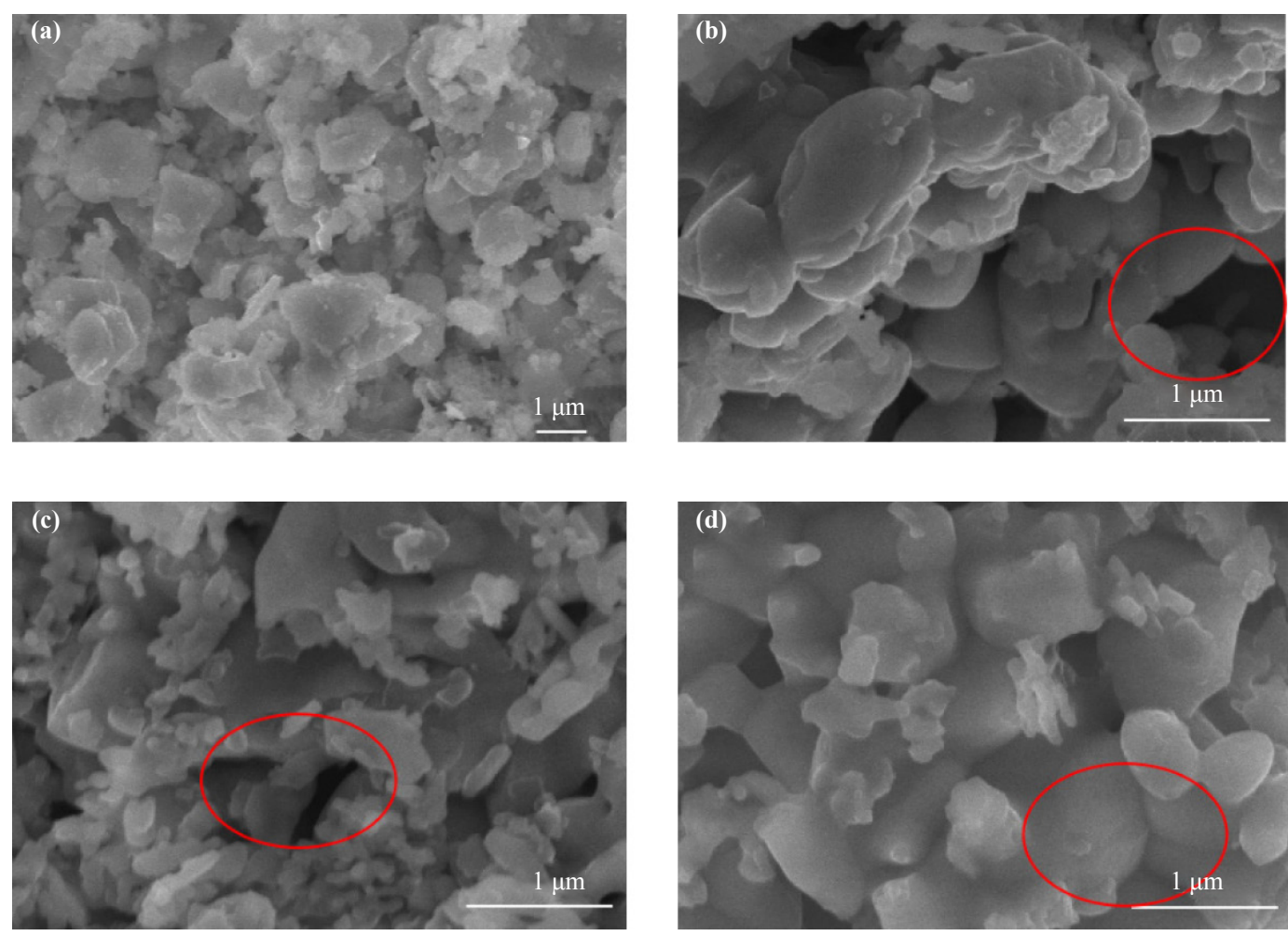

Figure 6. Scanning electron microscope characterization of fresh and reduced oxygen carrier at different reaction temperatures (a) fresh; (b) $850^{\circ} \mathrm{C}$; (c) $900{ }^{\circ} \mathrm{C}$; (d) $950^{\circ} \mathrm{C}$

\subsubsection{Mass ratio of oxygen carrier to coal}

At $900{ }^{\circ} \mathrm{C}$, the ratio of sludge to coal is constant, but the mass of OC was changed to oxygen carrier/coal $(\mathrm{O} / \mathrm{C})$. 
Figure 7 shows the effect of different $\mathrm{O} / \mathrm{C}$ on the concentration of each gas product in the effluent. With the increase in $\mathrm{O} / \mathrm{C}$, the $\mathrm{H}_{2}$ concentration in the outlet gas increased and then decreased. When $\mathrm{O} / \mathrm{C}$ reaches 5.80 , the $\mathrm{H}_{2}$ concentration reaches the highest. As a result, the export concentration of $\mathrm{CO}_{2}$ gradually increased, while the $\mathrm{CO}$ concentration gradually decreased. The main reason is that the carbon content in the raw material is constant. With the increase in OC, the total oxygen provided by the OC increases, and the oxygen obtained by the unit carbon molecule increases, thereby increasing $\mathrm{CO}_{2}$ production and decreasing $\mathrm{CO}$.

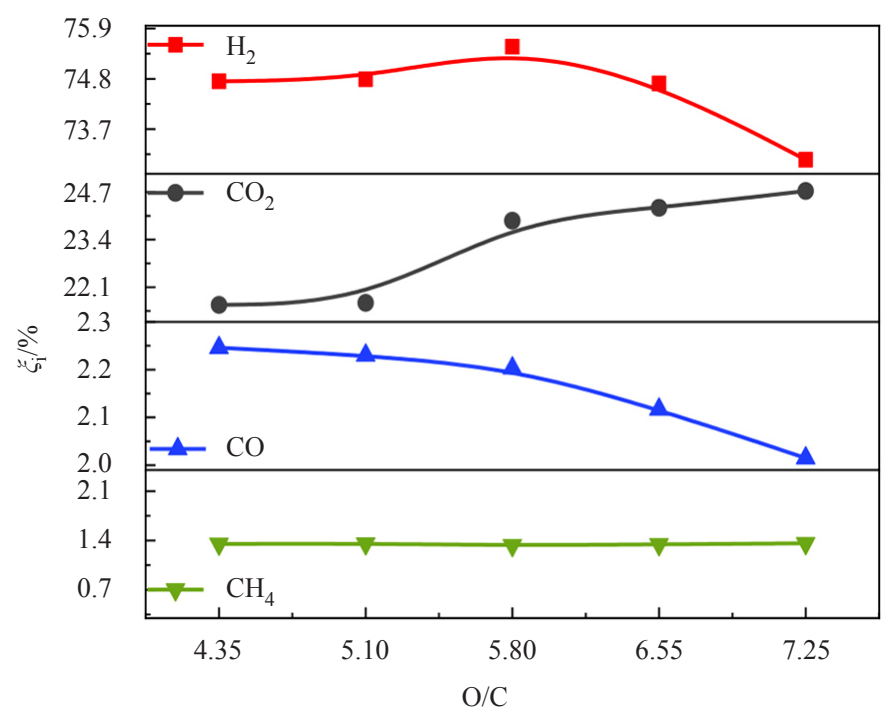

Figure 7. The effect of oxygen carrier/coal on the concentration of each gas product

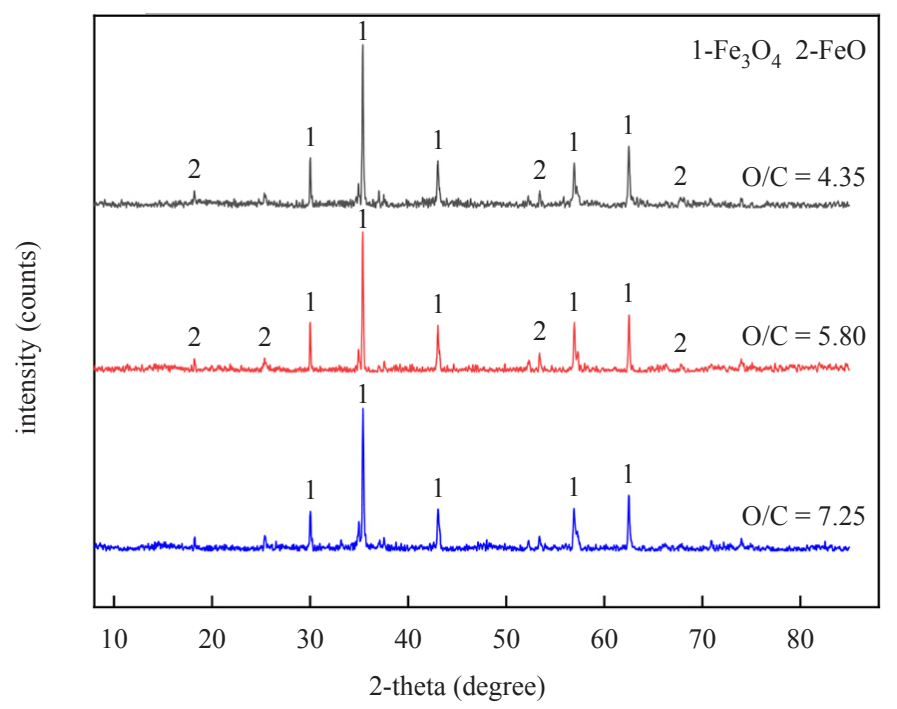

Figure 8. X-ray diffractometer characterization of oxygen carrier after reduction at different oxygen carrier/coal

The reduction order of $\mathrm{Fe}_{2} \mathrm{O}_{3}$ in iron-based OCs is $\mathrm{Fe}_{2} \mathrm{O}_{3} \rightarrow \mathrm{Fe}_{3} \mathrm{O}_{4} \rightarrow \mathrm{FeO} \rightarrow \mathrm{Fe}$. However, due to the weak reduction of reducing gases in the fuel reactor and thermodynamic constraints, the active components in iron-based OCs are generally reduced to $\mathrm{Fe}_{3} \mathrm{O}_{4}$ or $\mathrm{FeO}$. To explore the reason for $\mathrm{H}_{2}$ concentration change, the OC after reduction 
reaction was analyzed by XRD, such as Figure 8. The reduction degree of $\mathrm{Fe}_{2} \mathrm{O}_{3}$ decreases with the increase in $\mathrm{O} / \mathrm{C}$. When $\mathrm{O} / \mathrm{C}$ increased from 4.35 to 5.80 , the active components in the OC were reduced to $\mathrm{FeO}$ and $\mathrm{Fe}_{3} \mathrm{O}_{4}$. With the rise in $\mathrm{OC}$, the $\mathrm{OC}$ reduced to $\mathrm{FeO}$ in the reactor increased, and the $\mathrm{H}_{2}$ concentration increased. However, when the $\mathrm{O} / \mathrm{C}$ is greater than 5.80 , the $\mathrm{OC}$ in the reactor is very significant, $\mathrm{OC}$ is only reduced to $\mathrm{Fe}_{3} \mathrm{O}_{4}$, and the outlet gas $\mathrm{H}_{2}$ concentration decreases. It can be concluded that with the increasing of the oxygen carriers, the lattice oxygen content in the reactor gradually increases, and excessive oxygen carriers react with the undischarged $\mathrm{CO}$ and $\mathrm{H}_{2}$ in the reactor in redox reaction, oxidizing part of $\mathrm{CO}$ and $\mathrm{H}_{2}$ to $\mathrm{H}_{2} \mathrm{O}$ and $\mathrm{CO}_{2}$, increasing the concentration of $\mathrm{CO}_{2}$ in the outlet gas, while reducing the content of $\mathrm{CO}$ and $\mathrm{H}_{2}$.

Figure 9 shows the trend of syngas production at different $\mathrm{O} / \mathrm{C}$ ratios. When $\mathrm{O} / \mathrm{C}$ is less than 5.80, the $^{\mathrm{Fe}} \mathrm{O}_{2} \mathrm{O}_{3}$ in the OCs can promote the pyrolysis of tar and catalyze the water steam conversion reaction $\left(\mathrm{H}_{2} \mathrm{O}+\mathrm{CO}_{\rightarrow} \mathrm{CO}_{2}+\mathrm{H}_{2}\right)^{24}$, increasing the $\mathrm{H}_{2}$ production and the yield of syngas. However, with the further increase in $\mathrm{O} / \mathrm{C}$, the amount of oxygen provided by $\mathrm{OC}$ is very high, and part of $\mathrm{H}_{2}$ and $\mathrm{CO}$ in the syngas is oxidized to $\mathrm{H}_{2} \mathrm{O}$ and $\mathrm{CO}_{2}$, resulting in the decrease in outlet concentration, decrease in syngas production, and increase in $\mathrm{CO}_{2}$ concentration.

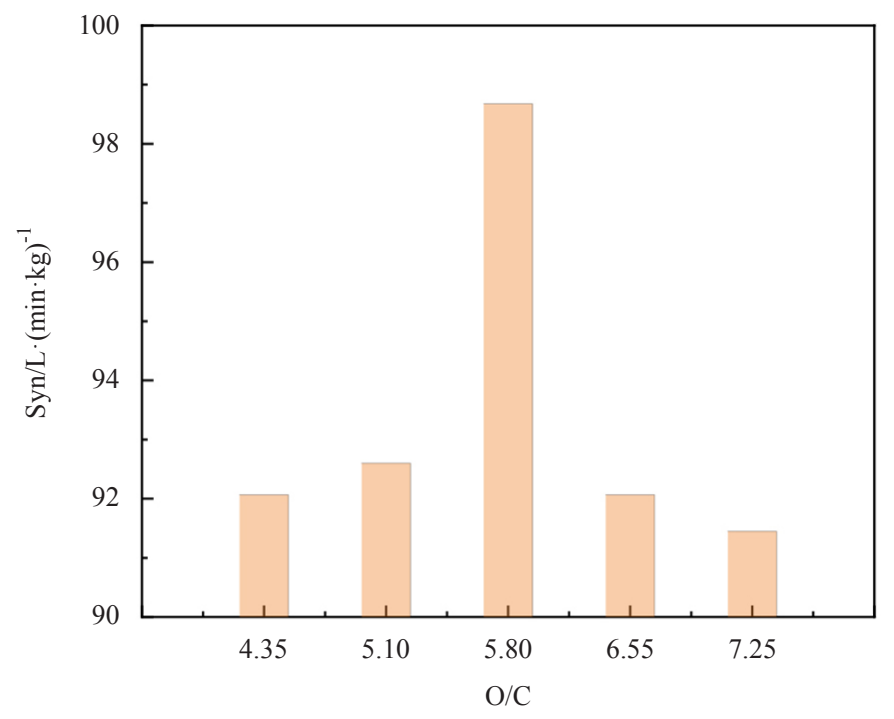

Figure 9. Variation of syngas yield with different oxygen carrier/coal ratios

\subsubsection{Sludge/coal mass ratio}

Sludge is a critical doping phase in the whole reaction system; in addition to a large amount of ash, other elements (such as $\mathrm{Fe}, \mathrm{Ca}, \mathrm{K}, \mathrm{Na}$, etc.) will affect the gasification process. Under the conditions of reaction temperature of $900{ }^{\circ} \mathrm{C}$, $\mathrm{O} / \mathrm{C}$ of 5.80, and water steam volume fraction of $72 \mathrm{vol} \%, \mathrm{~S} / \mathrm{C}$ was changed by fixing the mass of coal and $\mathrm{OC}$ and by changing the mass of sludge to explore the influence of sludge addition ratio on gasification reaction characteristics.

The relationship between the concentration of each gas product and the $\mathrm{S} / \mathrm{C}$ ratio is shown in Figure 10 . With the increase in $\mathrm{S} / \mathrm{C}, \mathrm{H}_{2}$ concentration increased and then decreased, $\mathrm{CO}_{2}$ concentration decreased and increased, $\mathrm{CO}$ concentration increased slightly, and $\mathrm{CH}_{4}$ concentration remained constant. When the sludge addition ratio was 0.2 , the $\mathrm{H}_{2}$ concentration reached the highest. When $\mathrm{S} / \mathrm{C}$ is small (0.1-0.2), a lot of $\mathrm{Fe}_{2} \mathrm{O}_{3}$ with oxygen-carrying function in sludge can improve the oxygen-carrying capacity to promote the gasification reaction rate, increase the concentration of $\mathrm{H}_{2}$, and decrease the concentration of $\mathrm{CO}_{2}$. When $\mathrm{S} / \mathrm{C}>0.2$, with the increase in sludge, a large amount of ash contained in sludge will adhere to the surface of the OCs, reducing the contact area of OCs with coal and other intermediate gas products. In addition, the deposited ash is dense, causing grain sintering and particle agglomeration of the OC, further reducing the contact area and slightly reducing the $\mathrm{H}_{2}$ concentration. 


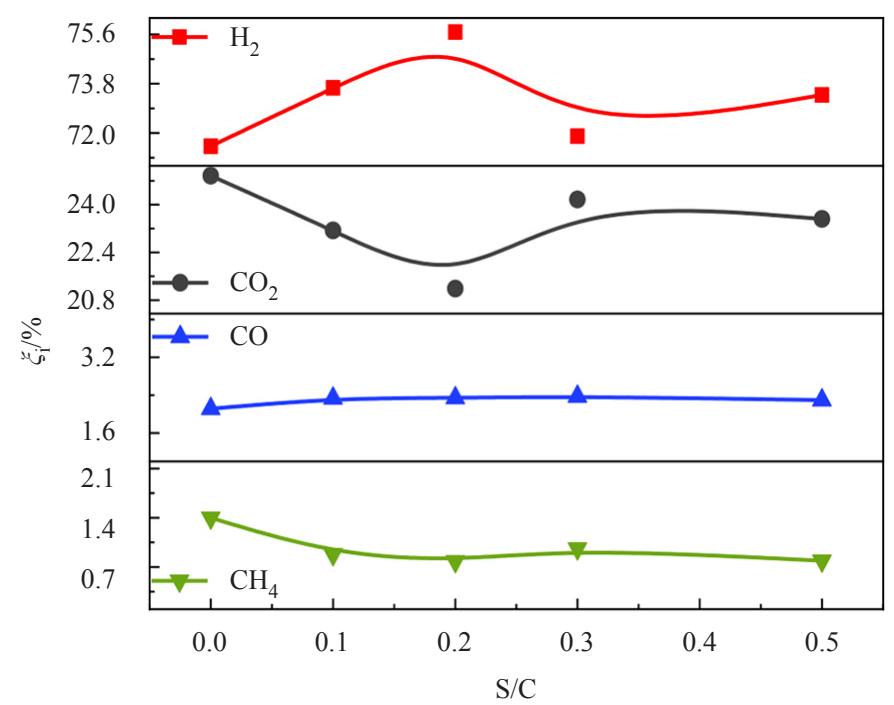

Figure 10. The effect of sludge/coal on gas product concentration

The SEM morphology of the OCs at S/C of $0.1,0.2$, and 0.5 was analyzed to observe the deposition of ash on the surface of the OCs. From Figure 11, with the increase in sludge addition ratio, the ash deposition on the surface of OC increases. When $\mathrm{S} / \mathrm{C}$ reaches 0.5 , the ash deposition on the surface of the OCs is severe, and the particle size increases, resulting in agglomeration. When $\mathrm{S} / \mathrm{C}$ is 0.2 , a high $\mathrm{H}_{2}$ concentration and large sludge treatment can be achieved.
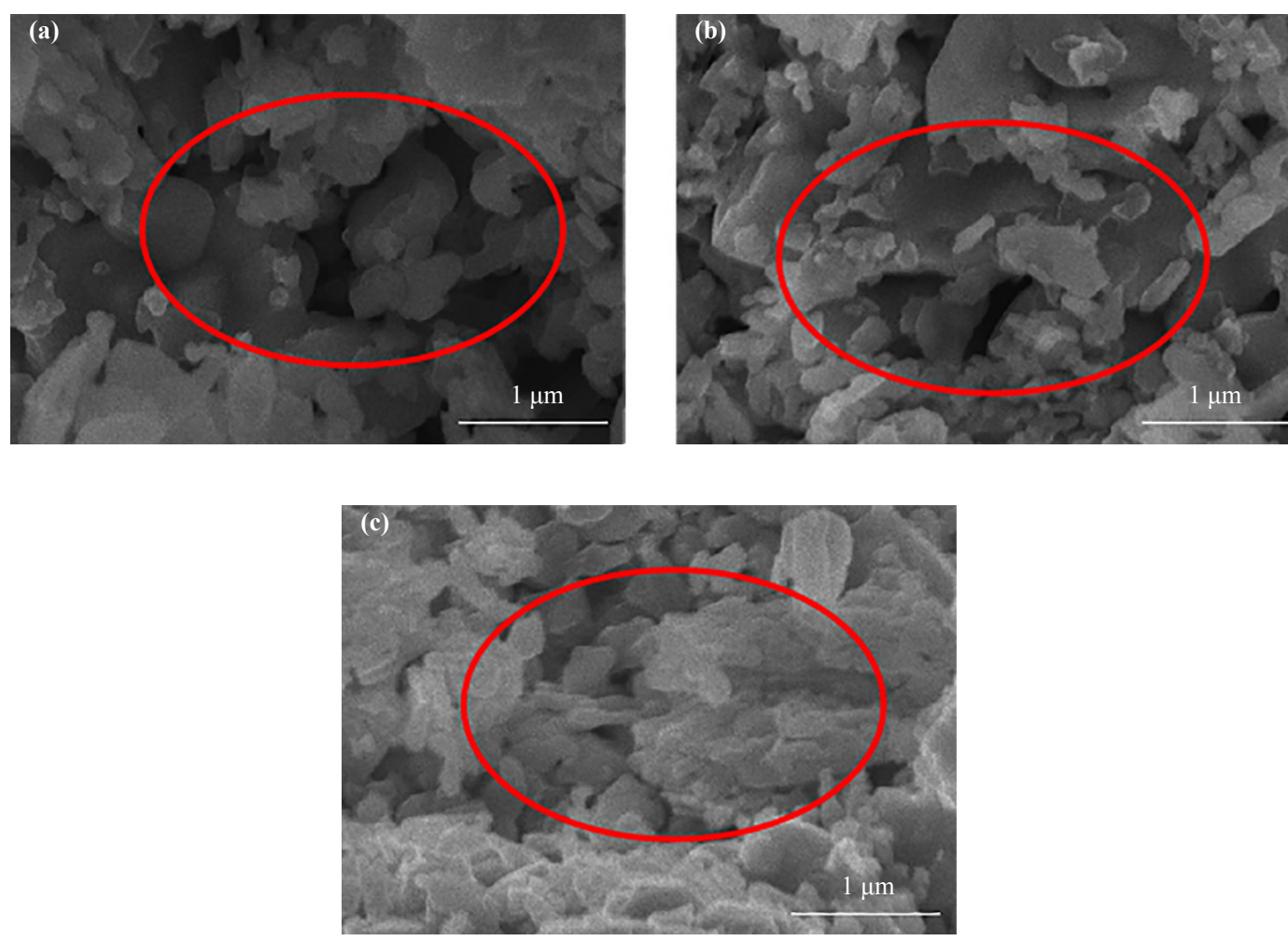

Figure 11. Scanning electron microscope results of reduced oxygen carriers at different sludge/coal (S/C) ratios (a) $\mathrm{S} / \mathrm{C}=0.1 ;$ (b) $\mathrm{S} / \mathrm{C}=0.2 ;$ (c) $\mathrm{S} / \mathrm{C}=0.5$ 


\subsection{Cyclic reaction characteristics of sludge/coal CLG}

Cyclic reaction ability is one of the indexes to evaluate OCs, and it is also an essential factor affecting process cost. Good OCs should maintain stable reaction performance in multiple cycles. ${ }^{25}$ To examine the cycle reaction characteristics of $\mathrm{Fe}_{7} \mathrm{Al}_{3} \mathrm{OC}$ and further explore the effect of sludge addition on the cycle reaction performance of OC, several cycles were carried out according to the operating conditions determined above.

The effects of eight CLG cycles on the gasification results were investigated by considering no sludge addition and sludge addition conditions.

Figure 12 shows the change in carbon conversion with the number of cycles when $\mathrm{Fe}_{7} \mathrm{Al}_{3}$ OCs react with coal, and coal and sludge at $900{ }^{\circ} \mathrm{C}$, respectively. From the figure, the OCs can maintain good reaction activity in the first four cycles after adding sludge, where the carbon conversion is not much different from that without adding sludge. However, the OCs without adding sludge after six cycles can still maintain good reaction activity and the carbon conversion of the OC after adding sludge decreases.

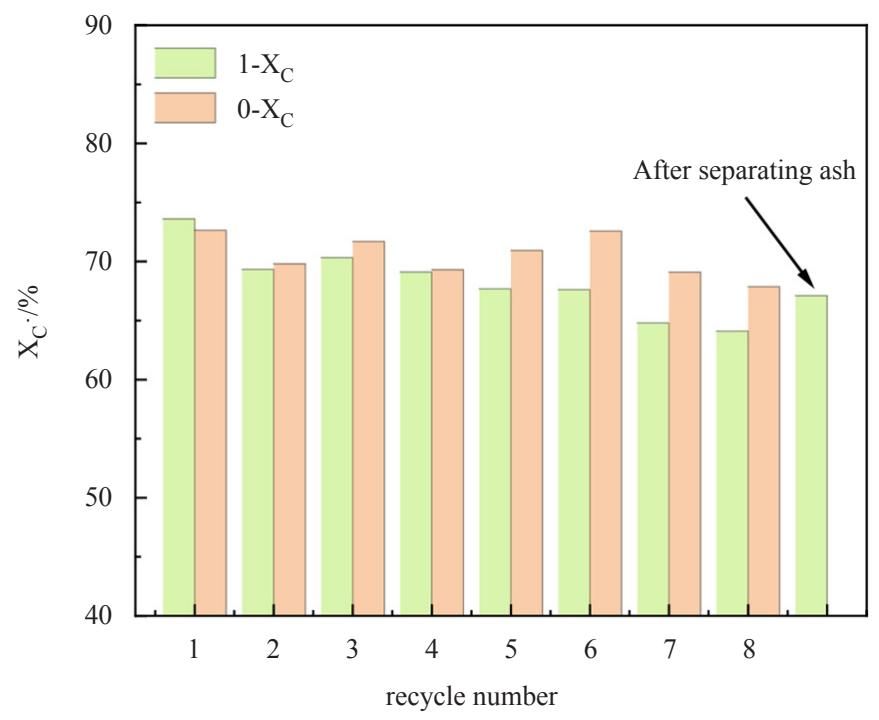

Figure 12. Change in carbon conversion in the cycle process $\left(\mathrm{O} . \mathrm{C}=0.8, \mathrm{~S} / \mathrm{C}=0.2, \varphi_{\mathrm{H}_{2} \mathrm{O}(\mathrm{g})}=72 \mathrm{vol} \%\right)$

0 -CLG experiment with coal as fuel

1-CLG experiment with coal and $20 \mathrm{wt} \%$ sludge

Figure 13 indicates that the syngas yield and $\mathrm{H}_{2}$ concentration after adding sludge are higher than those without adding sludge in the eight cycles. In the first six cycles, the redox performance of the OCs is good, and the syngas yield and $\mathrm{H}_{2}$ concentration in the outlet gas were nearly constant. However, after six cycles, the syngas yield and $\mathrm{H}_{2}$ concentration of the added sludge decreased slightly. To investigate this phenomenon, the carbon conversion was calculated by separating the loaded OCs from the bottom ash and reperforming the CLG reaction. Figure 12 shows that the OCs' activity after separation from the bottom ash was restored to a certain extent, indicating that the decrease in the OCs' reaction activity was due to the gradual deposition and attachment of large ash contained in the sludge to the surface of the OC during the cycle, reducing the gas-solid contact area and carbon conversion. 

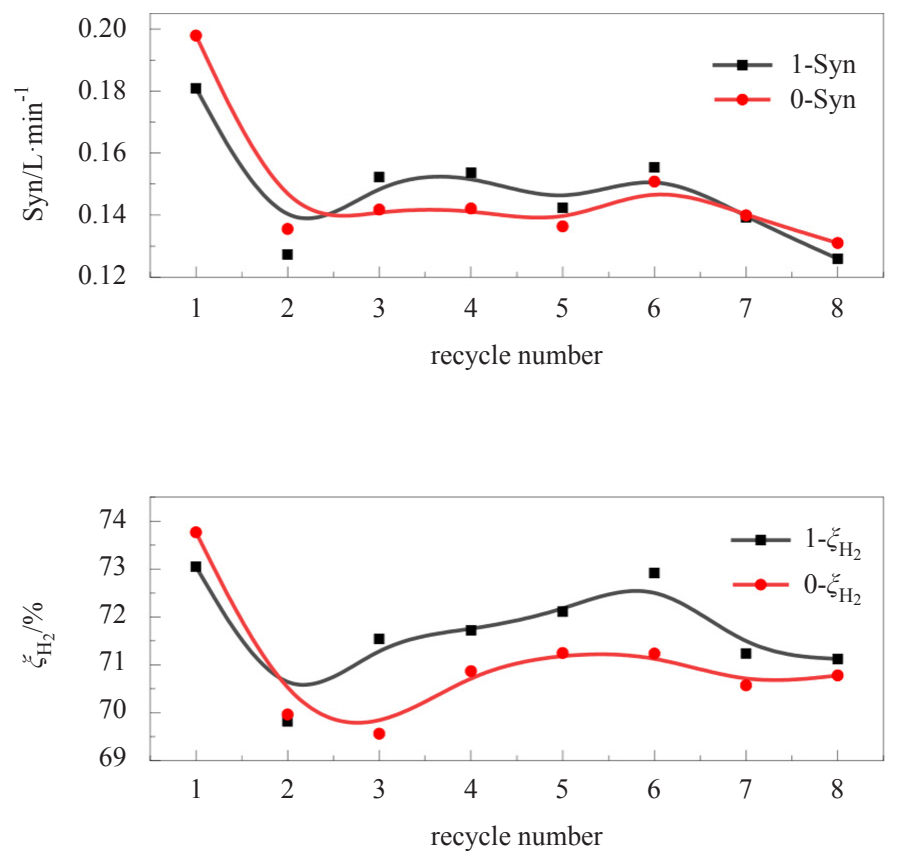

Figure 13. Changes of $\mathrm{H}_{2}$ concentration and syngas production during the cycle

Figure 14 shows the SEM characterization of OCs after five and eight cycles in two cases. The characterization of oxygen carriers in this paper is based on the full separation of ash. The specific operation is to take out the residue in the reactor after the end of the reaction, according to the different particle sizes of different kinds of substances, conduct sufficient vibration screening operation to ensure the physical separation of ash and oxygen carrier, remove the ash with smaller particle size and sludge with larger particle size, and characterize the remaining oxygen carrier. With or without sludge addition, with the increase in cycles, the agglomeration of OCs is gradually increased, and the deposition of surface ash is aggravated. Compared with nonsludge addition, the accumulation of OCs increased after sludge addition, and the deposition of surface ash increased, larger than that of fresh OCs. When no sludge was added, the iron-based OCs had good cycle performance and retained good morphology after eight cycles, consistent with the above conclusion. After adding sludge, due to the deposition of sludge ash, the agglomeration of OCs will be aggravated, resulting in further agglomeration. At the same time, during the cycle, a lot of sludge ash generated after sludge gasification adhered to the surface of OCs, resulting in a decrease in the contact area between OCs and gas intermediates, the reduction of redox ability, and reduction of carbon conversion.
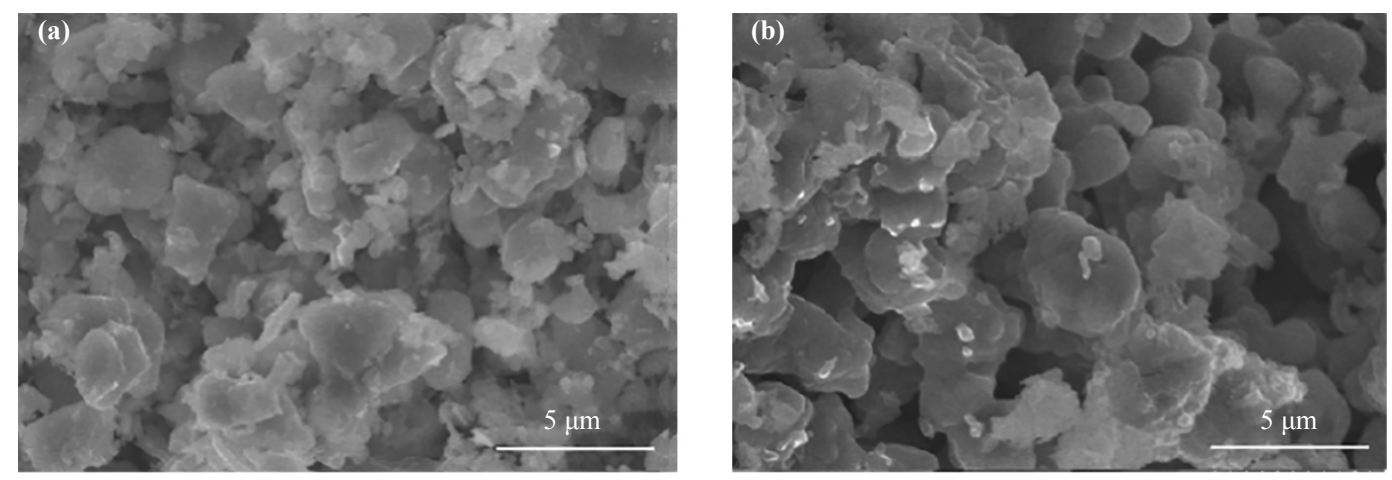

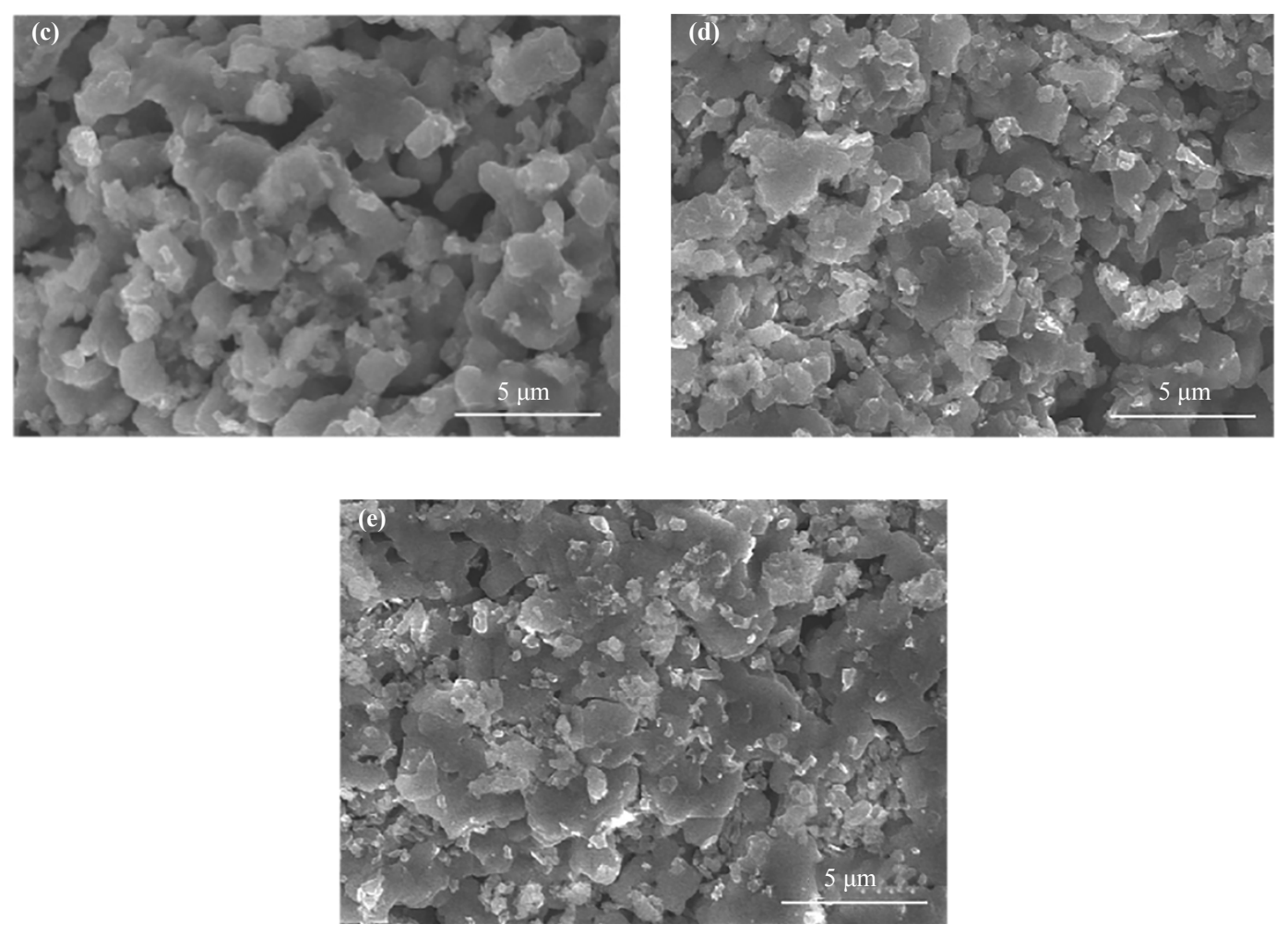

Figure 14. Analysis of scanning electron microscope results of oxygen loading after different cycles (a) fresh; (b) $0-5$; (c) $0-8$; (d) 1-5; (e) 1-8

Figure 15 shows the composition of the OCs' phase after eight cycles in two cases. The XRD diagram shows that the composition of the OCs after eight cycles in the two cases is the same, and there is only a slight difference in the content, indicating that the presence of sludge reduces the gas-solid contact area to a certain extent but does not change the composition of the OCs. In other words, under the condition of ensuring the timely separation of ash, the addition of sludge can increase the output of coal CLG syngas and increase the concentration of $\mathrm{H}_{2}$ in the outlet gas.

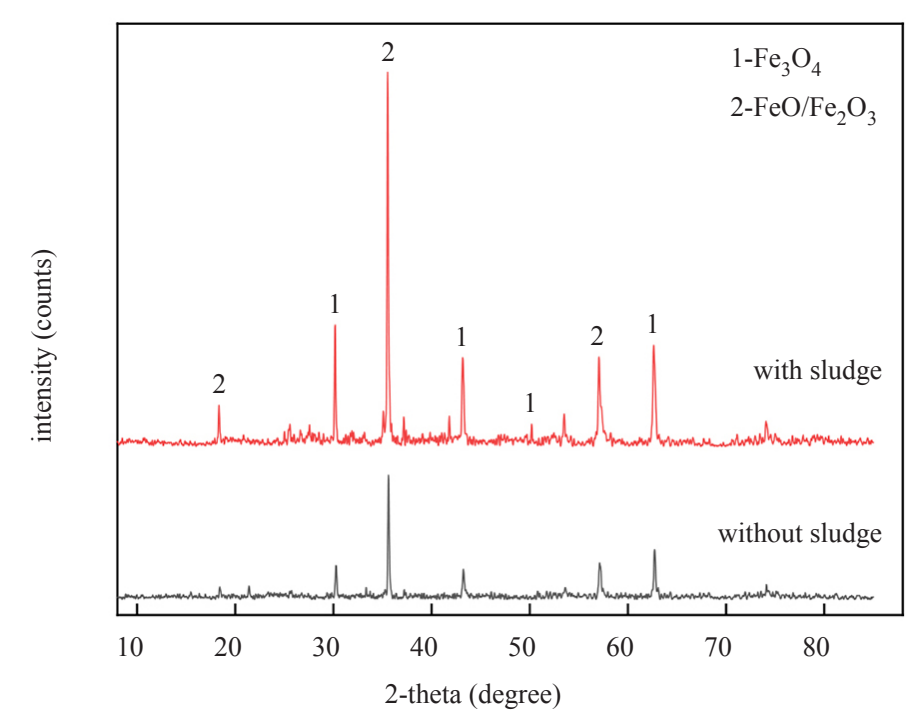

Figure 15. Analysis of X-ray diffractometer results of reduced oxygen carriers after eight cycles 


\subsection{Kinetics analysis}

The experimental data were fitted with various kinetic functions to obtain the kinetic model suitable for S/C CLG. On this basis, the kinetic parameters and equations of S/C CLG were further calculated to explore their reaction mechanism.

The experimental data were compared with three typical gas-solid kinetics models (RPM, VRM, and SCM), and the $\mathrm{S} / \mathrm{C}$ CLG process was fitted. Figure 16 shows the fitting condition at $850{ }^{\circ} \mathrm{C}$.
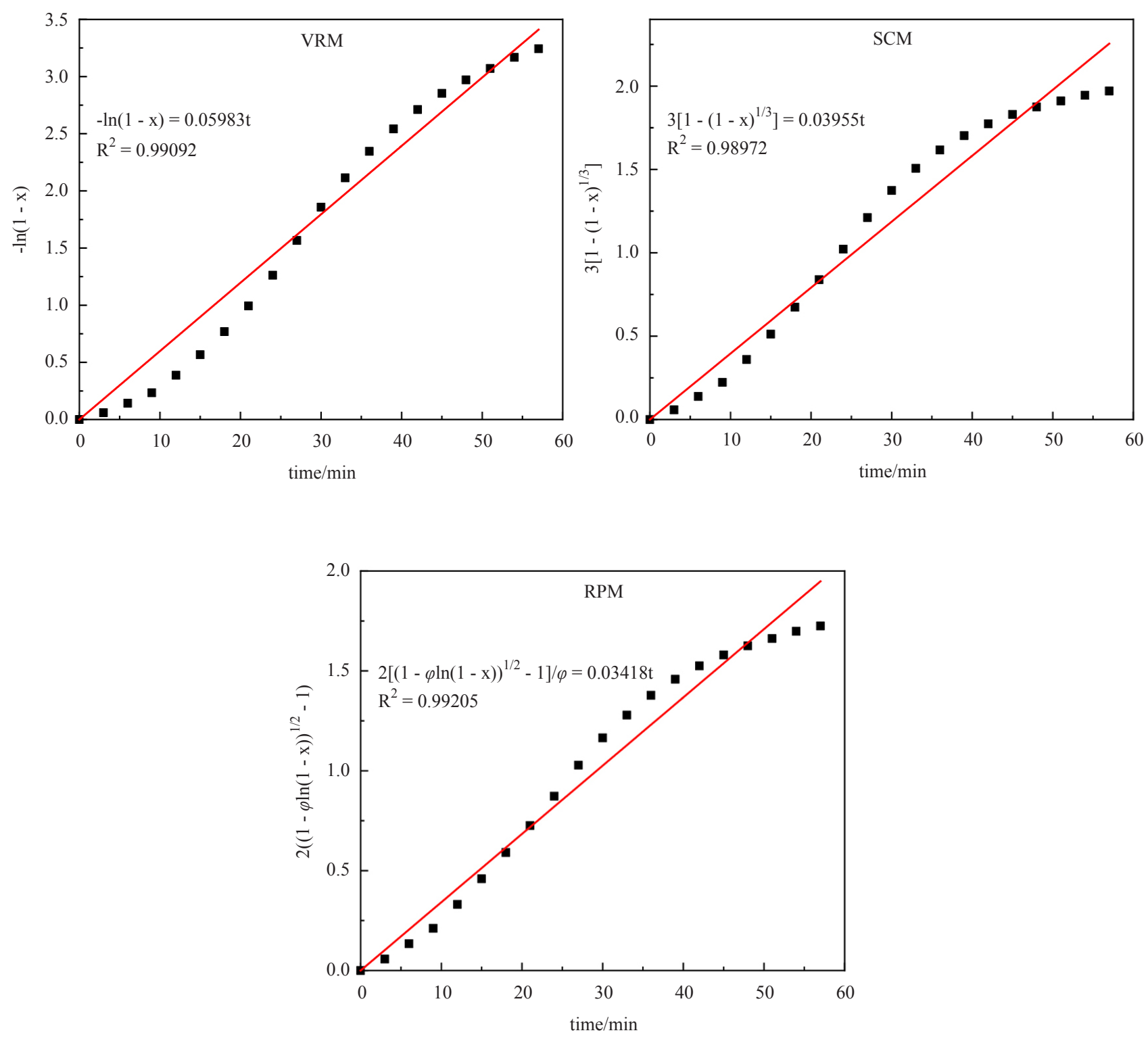

Figure 16. When the reaction temperature is $850^{\circ} \mathrm{C}$, the fitting of experimental data (scattered point) to model (solid line) is obtained

When the reaction temperature was $850^{\circ} \mathrm{C}$, the fitting effect of the VRM and the RPM was good, and the linear correlation coefficients $\mathrm{R}^{2}$ were greater than 0.99 , higher than those of the SCM. Table 4 shows the linear correlation coefficient $\mathrm{R}^{2}$ between different model methods and experimental data at different experimental temperatures after fitting different experimental temperatures by the same method. From Table 2, the $\mathrm{R}^{2}$ of the RPM and VRM is greater 
than that of the SCM at different reaction temperatures. It shows that the gas-solid reaction in S/C CLG is the same as the gas-solid reaction after the gas enters the solid particles. A change in the void structure of the solid particles will have a certain impact on the reaction rate of CLG. The fitting correlation coefficients $\mathrm{R}^{2}$ between the three models and the experimental data decreased to varying degrees with the increase in reaction temperature. It shows that the three models used in the calculation are more suitable for gas-solid reactions at lower reaction temperatures than hightemperature reactions. High temperature may cause changes in the pore structure and apparent morphology of solid particles and affect the gas-solid reaction rate.

Table 4. The correlation coefficients of models at different temperatures

\begin{tabular}{cccc}
\hline & & $\mathrm{T} /{ }^{\circ} \mathrm{C}$ & \\
\cline { 2 - 4 } Model & $850{ }^{\circ} \mathrm{C}$ & $900{ }^{\circ} \mathrm{C}$ & $950{ }^{\circ} \mathrm{C}$ \\
\hline Volume reaction model & 0.990 & 0.981 & 0.956 \\
Shrinking core model & 0.990 & 0.965 & 0.949 \\
Random pore model & 0.992 & 0.968 & 0.987 \\
\hline
\end{tabular}
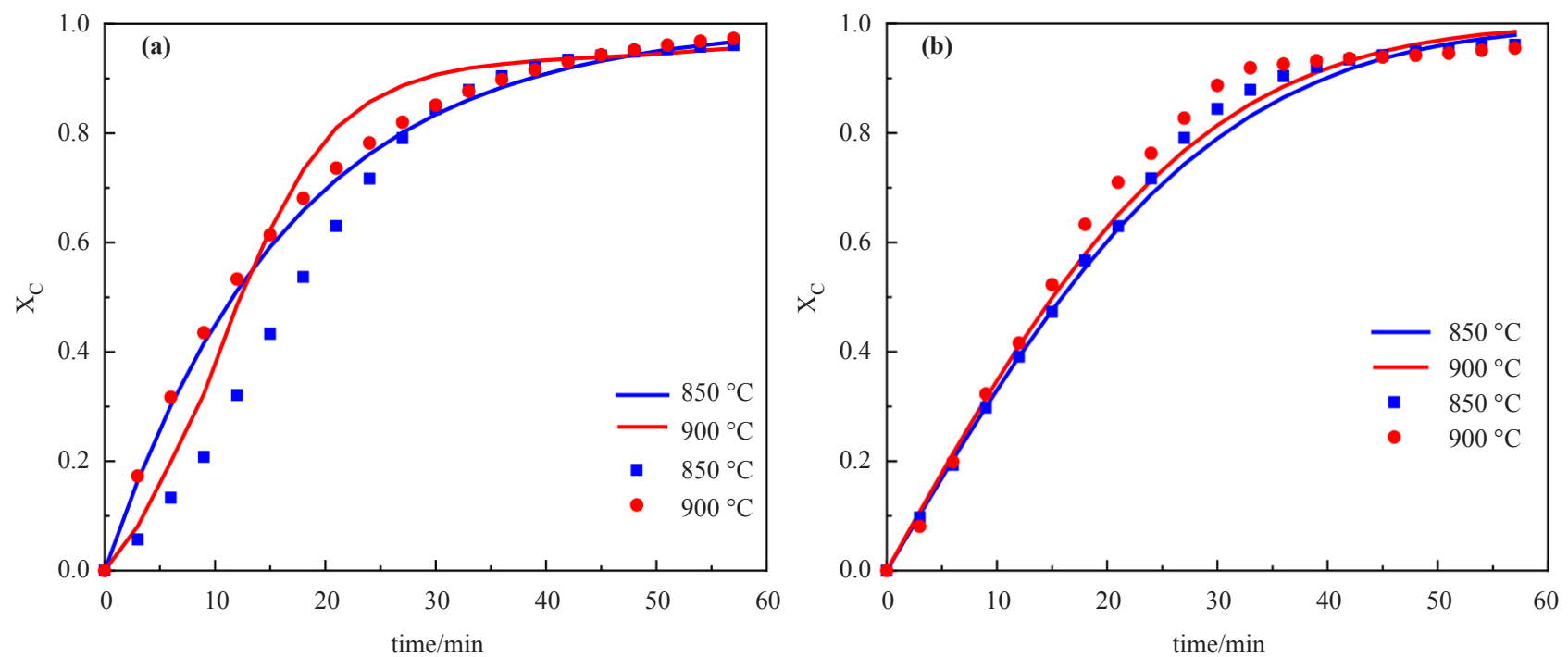

Figure 17. Volume reaction model (VRM), random pore model (RPM) calculation of conversion rate (solid line) and experimental conversion rate

(a) VRM model conversion rate and experimental conversion rate

(b) RPM model conversion rate and experimental conversion rate

To verify the model's accuracy, the constant $\mathrm{k}$ at different experimental temperatures was introduced into the expressions of VRM and RPM models. The model conversion rate is inversely calculated and compared with the experimental results. The comparison results are shown in Figure 17. Compared with the VRM, the carbon conversion calculated by the RPM is similar to the experimental carbon conversion, but when the carbon conversion is greater than $50 \%$, the actual carbon conversion is greater than the carbon conversion calculated by the RPM. The reason is that the alkali metals and minerals in sludge and coal ash play a certain role in promoting the gasification process later in the reaction. However, the addition of sludge in the coal CLG process plays a particular role in promoting the formation of the pore structure of coal char particles, thereby increasing the pore size of particles, the number of pores, and the gas-solid contact area, and thus speeding up the whole CLG reaction and carbon conversions. Therefore, the carbon 
conversion obtained by the experiment is higher than that calculated by the RPM.

Figure 18 represents the Arrhenius plot of the RPM model of S/C CLG. The activation energy Ea $=44.81 \mathrm{~kJ} / \mathrm{mol}$ and preexponential factor $\mathrm{A}=1.3504$ can be calculated using the linear fitting equation. According to the literature, ${ }^{26}$ the activation energy of coal char gasification in Xinjiang is $\mathrm{Ea}=47.81 \mathrm{~kJ} / \mathrm{mol}$ at atmospheric pressure, indicating that the addition of sludge reduces the activation energy of coal CLG.

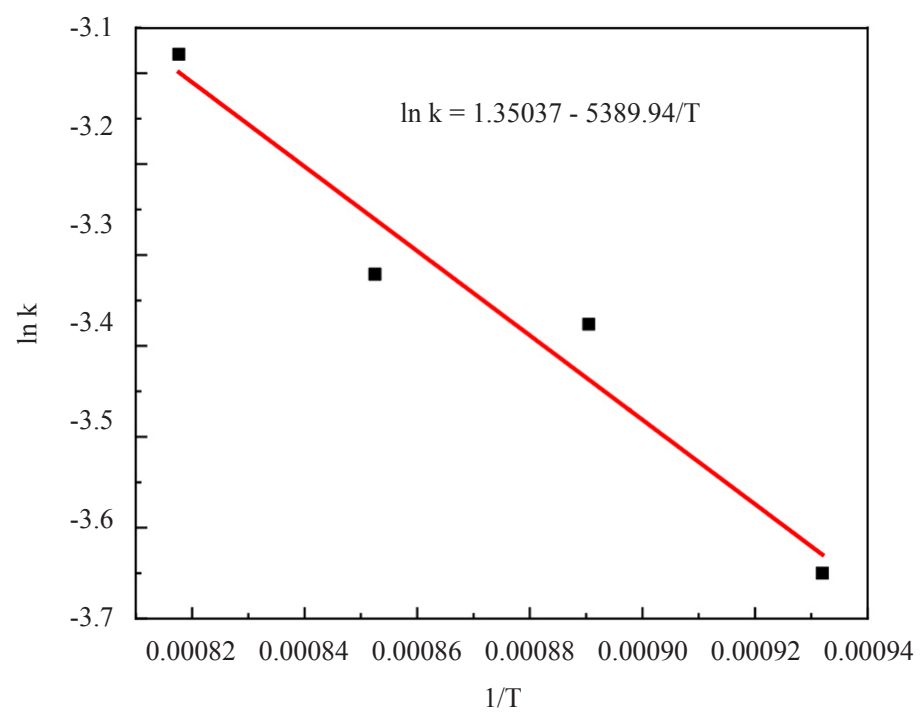

Figure 18. Arrhenius curve of sludge/coal CLG

\section{Conclusions}

(1) The optimum operating conditions of $\mathrm{S} / \mathrm{C} \mathrm{CLG}$ are $900{ }^{\circ} \mathrm{C}$ reaction temperature, $5.80 \mathrm{O} / \mathrm{C}$, and $0.2 \mathrm{~S} / \mathrm{C}$. Under these operating conditions, the concentration of $\mathrm{H}_{2}$ in the outlet gas reached $75.6 \mathrm{vol} \%$ and the yield of syngas reached $97.5 \mathrm{~L} \cdot \mathrm{min}^{-1} \cdot \mathrm{kg}^{-1}$.

(2) The cycle experiment was carried out under two conditions with and without sludge addition. During the eight cycles, the syngas production and $\mathrm{H}_{2}$ concentration after adding sludge were higher than those without adding sludge. However, in the first six cycles, the redox performance of the $\mathrm{OC}$ is good, and its syngas yield and $\mathrm{H}_{2}$ concentration in the outlet gas were constant.

(3) During the cycle, the addition of sludge resulted in large ash deposition on the surface of the OCs, reducing the gas-solid contact area and the reaction carbon conversion. However, after the ash in the reactor was separated and discharged, the reactivity of OCs improved to some extent. Furthermore, the addition of sludge did not affect the phase composition of the OCs, where the OCs' composition was the same after eight cycles in both cases.

(4) The S/C CLG process can be fitted using an RPM. Sludge can reduce the activation energy of coal CLG reaction, accelerate gasification reaction rate, and improve carbon conversion.

\section{Conflicts of interests}

The authors declare no conflict of interest. 


\section{References}

[1] Wang, Y.; Hu, J.; Ran, J.; Zhang, L.; Pu, G.; Tang, Q. Proc Chin Soc Elect Eng. 2007, 27, 44-50.

[2] Jiang, L.; Sun, S. Environ Sanit Eng. 2015, 23, 17.

[3] Dong, L.; Chang, J.; Zhang, Z.; Xu, P.; Yu, J.; Zhang, Y.; Dong, Y. Environ. Sci. Technol. 2020, 43, 137-144.

[4] Zhong, Z.; Jin, B.; Pei, H.; Dai, X.; Wang, J.; Huang, Y.; Wang, X. Chem Ind Eng Prog. 2018, 37, 2613-2619.

[5] Nishihara, T.; Nunoura, T.; Yamamoto, K.; Nakajima, F. Conference of Japan Society of Material Cycles \& Waste Management; Japan Society of Material Cycles and Waste Management, 2010.

[6] Li, W.; Li, M.; Li, W.; Liu, H.; Yu, Z. J. Fuel Chem. Techno. 2009, 37, 26-30.

[7] Zou, T.; Zhu, C.; Zhang, Y.; Lin, Y.; Liu, J.; Du, Y. J. Fuel Chem. Techno. 2020, 48, 137-143.

[8] Nipattummakul, N.; Ahmed, I.; Kerdsuwan, S.; Gupta, A. K. Appl. Energy. 2010, 87, 3729-3734.

[9] Menendez, J. A.; Dominguez, A.; Inguanzo, M.; Pis, J. J. J Anal Appl Pyrolysis. 2005, 74, 406-412.

[10] Garcia, G.; Arauzo, J.; Gonzalo, A.; Sanchez, J. L.; Abrego, J. Chem. Eng. J. 2013, 222, 345-352.

[11] Jeong, Y. S.; Choi, Y. K.; Park, K. B.; Kim, J. S. Energy. 2019, 185, 708-716.

[12] Luis, F.; Ortiz, M.; Adánez, J.; García-Labiano, F.; Abad, A.; Gayán, P. Chem. Eng. J. 2008, 144, 289-298.

[13] Rydén, M.; Lyngfelt, A.; Mattisson, T. Fuel. 2006, 85, 1631-1641.

[14] Liu, Y.; Guo, Q. Chinese J Chem Eng. 2013, 21, 127-134.

[15] Liu, Y.; Guo, Q.; Cheng, Y.; Ryu, H. J. Ind. Eng. Chem. Res. 2012, 51, 10364-10373.

[16] Guo, Q; Cheng, Y.; Liu, Y.; Jia, W.; Ryu, H. J. Ind. Eng. Chem. Res. 2014, 53, 78-86.

[17] Cheng, Y.; Liu, Y.; Tian, H.; Guo, Q. J Chem Ind Eng. 2013, 64, 2587-2595.

[18] Mei, D.; Zhao, H.; Ma, Z.; Zheng, C. J Fuel Chem Techno. 2012, 40, 795-802.

[19] Huang, Z.; He, F.; Li, H.; Zhao, Z. J. J Fuel Chem Techno. 2012, 40, 300-308.

[20] Huang, Z.; He, F.; Zheng, A.; Zhao, K.; Chang, S.; Zhao, Z.; Li, H. Energy. 2013, 53, 244-251.

[21] Wu, J.; Shen, L.; Xiao, J.; Wang, L.; Hao, J. J Chem Ind Eng. 2009, 60, 2080-2088.

[22] Zhang, Y.; Liu, Y.; Yang, Q.; Duo, Q. J Chem Ind Eng. 2016, 67, 1303-1312.

[23] Yu, Z.; Li, C.; Jing, X.; Zhang, Q.; Fang, Y.; Zhao, J.; Huang, J. Energy Fuels. 2013, 27, 2703-2711.

[24] Chen, L.; Yang, L.; Liu, F.; Nikolic, H. S.; Fan, Z.; Liu, K. Fuel Process. Technol. 2017, 156, 185-194.

[25] Adánez, J.; de Diego, L. F.; García-Labiano, F.; Gayán, P.; Abad, A.; Palacios, J. M. Energy Fuels. 2004, 18, 371 377.

[26] Chen, J.; Chen, W.; Ji, R.; Jiao, Y.; Wang, X. Int J Green Energy. 2019, 16, 1144-1151. 